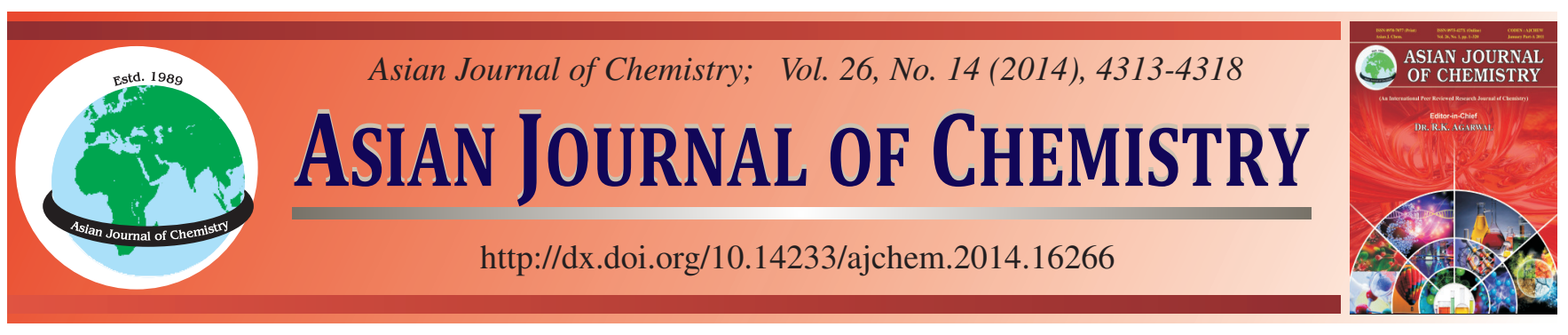

\title{
Comparative Extraction and Downstream Processing Techniques for Quantitative Analysis of Rosmarinic Acid in Rosmarinus officinalis
}

\author{
Arnab Chatterjee, Sudeep Tandon and Ateeque Ahmad*
}

Process Chemistry and Technology Department, CSIR-Central Institute of Medicinal and Aromatic Plants, P.O. CIMAP, Lucknow-226 015, India *Corresponding author: E-mail: ateeque97@gmail.com

Evaluation of different extraction and downstream processing techniques for the optimized extraction and quantification of rosmarinic acid (RA) in rosemary leaves has been reported. Quantitative analysis was accomplished on a Waters symmetry $\mathrm{C}_{18}(150 \times 3.9 \mathrm{~mm}$ i.d., 5 $\mu \mathrm{m})$ column using $0.1 \%$ formic acid in water and methanol as mobile phase under linear gradient elution at $330 \mathrm{~nm}$. Method represented a greater degree of linearity $\left(r^{2}=0.99\right)$ and precision with satisfactory recoveries $(98.35-101.33 \%)$. Extractive process development showed alcohol/water (7:3) as the optimum combining ratio during solvent optimization parameters in terms of extraction efficiency at ambient conditions (14.17-19.83 $\left.\mathrm{\mu g} \mathrm{g}^{-1}\right)$. Ultrasonic-assisted extraction showed a two fold enhancement in the content of rosmarinic acid $\left(45.55 \mu \mathrm{g} \mathrm{g}^{-1}\right)$ for $70 \%$ aqueous methanol whereas a three fold enhancement $\left(48.09 \mu \mathrm{g} \mathrm{g}^{-1}\right)$ was observed for microwave-assisted extraction in $70 \%$ aqueous ethanol combination. Novelty of the downstream enrichment technique uses the adoption of a solid-matrix partitioning technique which subtantially enhanced the content of rosmarinic acid during sequential solvent partitioning.

Keywords: Rosmarinus officinalis, Energy assisted extraction techniques, Rosmarinic acid, Solid matrix partitioning technique. ᄂ - - - - - - - - - - - - - - - - - - - - - - - - -

\section{INTRODUCTION}

Rosemary, Rosmarinus officinalis, one of two species in the genus Rosmarinus, is a woody, perennial herb with fragrant, evergreen, needle-like leaves and white, pink, purple or blue flowers, native to the Mediterranean region. It is a member of the mint family Lamiaceae which includes many other herbs. Rosemary is used as a decorative plant in gardens and has many culinary and medical uses. The leaves are used to flavor various foods, like stuffings and roast meats. Rosemary contains antioxidant compounds such as carnosic acid, rosmarinic acid (RA) apart from other bioactive compounds including camphor, caffeic acid, ursolic acid, betulinic acid, rosmaridiphenol and rosmanol $^{1-3}$. Some of these compounds have shown positive results and may be useful in preventing or treating cancer, strokes and Alzheimer's disease. Researchers have reported that the plants are a source of several compounds having antioxidant $^{4}$, antiinflammatory ${ }^{5}$, antiallergy ${ }^{6}$ and antidepressive ${ }^{7}$ activities. Phenolic compounds have also been reported amongst which, rosmarinic acid an ester of caffeic acid and 3,4dihydroxyphenylacetic acid are the most important compounds ${ }^{8}$.

Rosmarinic acid from Rosmarinus officinalis is elucidated to be an ester of caffeic acid and 3,4-dihydroxyphenyllactic acid $^{9}$. Because of the antioxidant activity of Lamiaceaeous herbs in laboratory test models they have been suggested to have beneficial effects in humans ${ }^{10}$. Rosmarinic acid has also been reported to possess several biological activities i.e. antiviral, antibacterial, antiinflammatory and antioxidant ${ }^{11}$. Rosmarinic acid is also a potential anxiolytic agent as it acts as a GABA transaminase. The presence of rosmarinic acid in medicinal plants, herbs and spices has beneficial and health promoting effects. In plants, rosmarinic acid is supposed to act as a performed constitutively accumulated defense compound ${ }^{12}$.

Polyphenolic compounds with antioxidant activity from different parts of Rosmarinus officinalis have also been reported $^{13}$. Several references are available for identification and determination of rosmarinic acid in plant sources ${ }^{12,14,15}$. In the present studies, an improved HPLC method has been developed keeping in view a complete baseline separation of related polar phenolics using mild acidic conditions which often co-elute in the earlier reported processes. Although, a number of processes have been extensively described for the extraction of rosmarinic acid, it either involved chemical derivatization of the aqueous extracts as a lead salt ${ }^{16}$ or enrichment after chromatography on polyamide ${ }^{17}$. A patented process also involves cumulative dissolution steps and in particular relates to the plant Melissa officinalis having the highest rosmarinic acid content ${ }^{18}$. Herein the present study we have optimized solvent ratio parameter by taking different alkanol/aqueous mixtures guided by previous studies on the PLE (pressurised 
liquid extractions $)^{19}$, deciphering ethanol and water as the best solvent for extracting rosmarinic acid in the pressurised extraction at $100-150{ }^{\circ} \mathrm{C}$. The aim of the present study is to develop an energy efficient extraction technology considering low boiling, easily recyclable alkanol solvents depending on the chemical integrity of the aliquot. Comparative evaluation of energy assisted extracting processes like MAE (Microwave assisted extraction) and UAE (Ultrasonic assisted extraction) was done for analysing the extractibility profile of rosmarinic acid in various extraction methods using solvents or a combination of solvents. Application of a new advertent partitioning technique using a solid-matrix of high porosity reduced the complexity of sample matrix which significantly enriched the content of rosmarinic acid. Thus, an economic process technology using solid-matrix partitioning technique and user friendly conditions enhancing the target compound has been reported for the first time in the present findings.

\section{EXPERIMENTAL}

Fresh leaves of rosemary were collected in April 2012 from CSIR-CIMAP Research Centre at Purara, District Bageshwar Uttarakhand, India. Samples of leaves were authenticated by Pharmacognosy department of CIMAP and voucher specimen was deposited. The shade dried plant material was stored in dry place at room temperature following good storage practices until use.

The solvents used in the extraction process were of laboratory grade and were procured from Loba Chemie, Mumbai, India. Before use, the solvents were distilled following general laboratory scale distillation procedures. HPLC grade Methanol and water were procured from Merck, Mumbai, India. The solvents were filtered through a $0.45 \mu \mathrm{m}$ Millipore membrane (Millipore, Billerica, MA) before injecting into the HPLC stream. Analytical grade formic acid (Loba Chemie, Mumbai, India) was used. The external standard of rosmarinic acid (93\% purity, HPLC analysis) was procured from M.P. Biomedicals, Ohio, US.

Soxhlet extraction (hot percolation): Sample of milled, dry rosemary leaves $(5 \mathrm{~g})$ was extracted in soxhlet apparatus (J-SIL, Mumbai) with ethanol $(3 \times 100 \mathrm{~mL}, 8 \mathrm{~h})$ in a thermostatically controlled water bath at $80^{\circ} \mathrm{C}$. The hot percolation process was performed to check the variation in the initial content of rosmarinic acid for comparison with cold percolated ethanolic extraction process.

Ultrasonic assisted extraction (UAE): Ultrasonic extraction was carried out on pulsed acoustic waves (Sonics VCX750, Vibra cell®, Sonics and Materials Inc., Newtown, CT, USA, $20 \mathrm{kHz}, 750 \mathrm{~W}, 40 \%$ amplitude, $10 \mathrm{~s} / 10 \mathrm{~s}$ pulse, sonic power $14.93 \mathrm{~W} \mathrm{~cm}^{-2}$, PZT probe $13 \mathrm{~mm} \mathrm{dia).} \mathrm{Pulsed} \mathrm{acoustic}$ waves with an amplitude of $40 \%$ and $10 \mathrm{~s} / 10 \mathrm{~s}$ pulse mode was imposed on $5 \mathrm{~g}$ of finely milled dried leaves in a ethanol/ methanol water ratio $(7: 3)(3 \times 100 \mathrm{~mL}, 1 \mathrm{~h})$ giving the highest rosmarinic acid content as optimized by the normal ambient cold percolation studies. Two experimental conditions was adopted at an extraction temperature of $60{ }^{\circ} \mathrm{C}$ and $80{ }^{\circ} \mathrm{C}$ to study the effect of temperature on extractive yield keeping acoustic mode same.

Microwave assisted extraction (MAE): Microwave assisted extractions were carried out in microwave oven (C103FL,
Samsung) having programmable microwave radiation energy $(900,600,450,300,180$ and $100 \mathrm{~W})$ taking $5 \mathrm{~g}$ of finely milled shade dried leaves $(3 \times 100 \mathrm{~mL}$ at $900,600,450,300$ $\mathrm{W}$ for $3 \mathrm{~min}$ ) in ethanol and methanol/water ratio of $(7: 3)$. The solvent extracts were allowed to cool down at room temperature and evaporated to dryness in a rotary vacuum evaporator at $40{ }^{\circ} \mathrm{C}$.

Standard stock solutions and sample preparation: All extracts obtained after different extractive methods were concentrated under vacuum at $40{ }^{\circ} \mathrm{C}$ and sample solutions of $1 \mathrm{mg}$ $\mathrm{mL}^{-1}$ were prepared in methanol or methanol/water ratio. The standard stock solution of $1 \mathrm{mg} \mathrm{mL}^{-1}$ was prepared after dissolving rosmarinic acid in methanol. Working solutions for method validation were prepared after appropriate dilution of the stock. All samples were filtered through $0.45 \mu \mathrm{m}$ Millipore membrane prior injection for HPLC analysis.

HPLC analysis: The HPLC system (Shimadzu, Japan) consisted of a U.V. detector (SPD-10A), binary gradient pumps (LC-10 AT), column oven (CTO-10 AS), degasser along with an interface (CBM-20 A). The HPLC separation was achieved on a Waters symmetry $C_{18}$ column $(3.9 \times 150 \mathrm{~mm}, 5 \mu \mathrm{m})$ with a mobile phase composition of water and methanol both containing $0.1 \%$ formic acid (v/v) as solvent A and B in a gradient elution mode. The method initially started with $40 \% \mathrm{~B}$ with a flow rate of $0.8 \mathrm{~mL} \mathrm{~min}^{-1}$ and increased to $60 \% \mathrm{~B}$ linearly until $10 \mathrm{~min}$. The flow rate was reduced to $0.6 \mathrm{~mL} \mathrm{~min}^{-1}$ at 10.01 min thereby increasing the concentration of B to $100 \%$ till $35 \mathrm{~min}$ in a linear gradient mode. The condition was maintained for another 10 min with an increased flow rate of $0.8 \mathrm{~mL} \mathrm{~min}^{-1}$ for adequate column washing thereby finally reverting to the original condition by $50 \mathrm{~min}$. Column temperature of $30^{\circ} \mathrm{C}$ was maintained throughout the run. Data acquisition was performed at $330 \mathrm{~nm}$ by injecting $10 \mu \mathrm{L}$ volume of each reference rosmarinic acid and sample solution through a manual injector keeping the injection volume constant for all analysis. Data acquisition and analysis were performed through LC-Solution software.

\section{RESULTS AND DISCUSSION}

Slow gradient for complete resolution of sample matrix: Different combinations of solvent systems including methanol-water were selected depending upon literature survey. In a recent method ${ }^{15}$ Rosemary officinalis plant from the Indian subcontinent showed more complexity in the sample matrix revealing a vast array of several other major bioactive constituents apart from rosmarinic acid. The longer range runtime of 50 min offered a detailed profiling of sample matrix. Several acid additives like acetic acid, formic acid were tried but the optimum resolution of the complete extract was achieved with $0.1 \% \mathrm{HCOOH}$ without compromising on the baseline resolution of the detected analytes and their peak symmetry and shape. The modified method developed herein allows the quantification of the other major constituents in the sample matrix apart from rosmarinic acid without the interference of any other peaks in the sample matrix. A little tailing effect was observed with other organic acid modifiers but was minimized with the said concentration of $\mathrm{HCOOH}$ with a tailing factor $\left(\mathrm{T}_{\mathrm{f}}\right)$ of 1.21. It can be observed that good separation was achieved for different analytes within an analysis 
time of 50 min ensuring an effective fingerprint of other marker constituents. The slow gradient was devised for a complete resolution of the chromatogram for the successive quantification of the major analytes ensuring sufficient column washing thereby achieving a good reproducibility in the retention time (Fig.1).
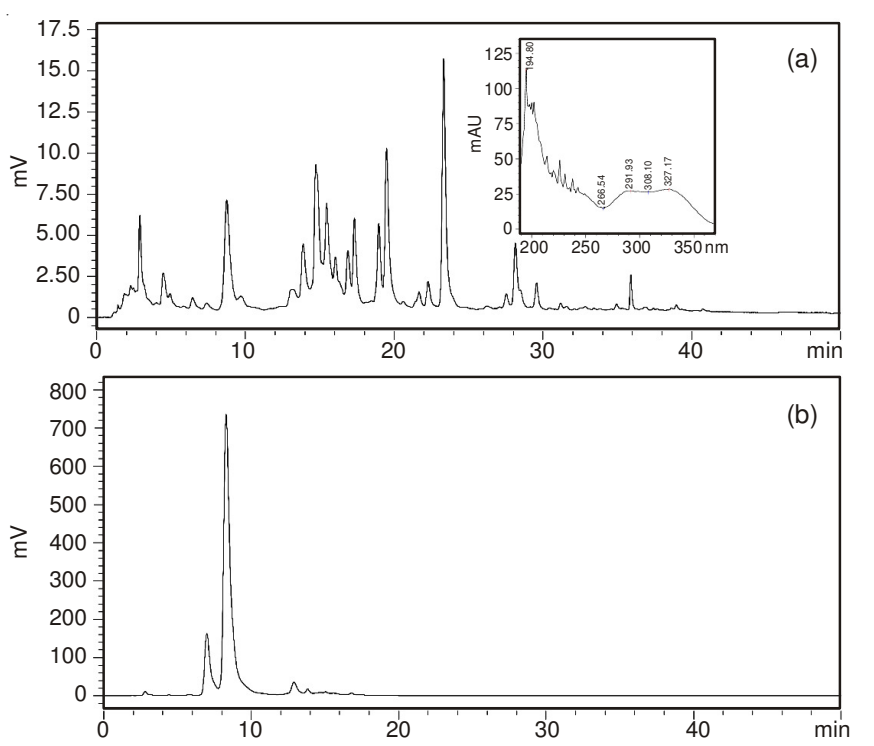

Fig. 1. (a) Representative HPLC chromatogram of cold percolated $70 \%$ ethanolic extract, and (b) Standard rosmarinic acid (r. t. $=8.4 \mathrm{~min}$ )

LC method validation: Validation was performed in compliance with International Conference on Harmonization and IUPAC using adequate statistical estimates (\%RSD, least square regression and residual analysis) $)^{20-22}$.

Linearity and sensitivities (LOD and LOQ): The linearity of the detector response was determined based on calibration curves. Five test solutions ranging from $5 \mu \mathrm{g} \mathrm{mL}^{-1}$ to $60 \mu \mathrm{g} \mathrm{mL}$ were prepared by dilution of the original stock solution of $1 \mathrm{mg} \mathrm{mL}^{-1}$. The linear regression curve was obtained by plotting the UV detector response in terms of peak area of rosmarinic acid at each level (y-axis) against the concentration ( $\mathrm{x}$-axis) of each injection. A good correlation $\left(r^{2}=0.9991\right)$ was found on computation. Limits of detection (LOD) and limits of quantification (LOQ) were determined using the linear regression equation. The following equations were applied: $\mathrm{LOD}=3.3$ $\sigma / \mathrm{b}$ and $\mathrm{LOQ}=10 \sigma / \mathrm{b}$, where $\sigma$ is residual standard deviation of the regression line (RSDR) and $b$ is the slope of the calibration curve $e^{23}$. The LOD within a linearity of 0.9991 was calculated to be $2.22 \mu \mathrm{g} \mathrm{mL}^{-1}$ and LOQ was $6.74 \mu \mathrm{g} \mathrm{mL}^{-1}$.

Precision and accuracy: Intra-day and inter-day precision were determined by assaying standard solution of rosmarinic acid at two different concentrations (10 and $\left.20 \mu \mathrm{g} \mathrm{mL}^{-1}\right)$ used for the calibration curve. The intra-day and inter-day precision values of measured concentration of rosmarinic acid were calculated from linearity plots. In both the cases the relative standard deviation (RSD) values are approximately $\leq 2$ which are considered to be precise. The accuracy of the method was tested in terms of recovery percentage. Recovery of rosmarinic acid was evaluated at two alcoholic extracts (methanolic and ethanolic) concentrations of $1 \mathrm{mg} \mathrm{mL}^{-1}$ each the equivalent rosmarinic acid content of which is 12.48 and $6.50 \mu \mathrm{g}$. A known amount $(0.25 \mu \mathrm{g})$ of rosmarinic acid from the stock solution of $5 \mu \mathrm{g} \mathrm{mL} \mathrm{m}^{-1}$ was added to both the alcoholic extracts of the sample. A percentage RSD value was determined as the difference between measured and expected values. The average recoveries with \% RSD values are presented in (Table-1).

Statistical analysis: Data were processed and recorded as means \pm C.V. (\% RSD) of triplicate measurements. All the statistical analysis has been performed in MS-EXCEL 2007.

Robustness of the developed method: The method developed was tested for small variations in composition and temperature of the analysis as the two variables for a gradient method. The instrumental RSD \% for the peak area and R.T. were calculated for the small and deliberate changes in the acid concentration and also in the temperature of analysis. The analysis of the data shows the robustness of the developed method (Table-2).

Comparison of different solvents for extraction of rosmarinic acid: Comparative extraction graphical analysis shows that the maximum extractability of the analyte (rosmarinic acid) was achieved using $70 \%$ methanol and $70 \%$ ethanol as the modified solvents. Variation in extraction efficiency by

\section{TABLE-1}

OVERVIEW OF THE METHOD DEVELOPMENT FOR QUANTIFICATION OF RA IN THE SAMPLE OF ROSEMARY LEAVES

\begin{tabular}{|c|c|c|c|c|}
\hline \multicolumn{5}{|l|}{$\begin{array}{l}\text { Retention time/(min) (mean } \pm \text { S.D. }) \\
\text { Linearity }\end{array}$} \\
\hline Working concentration range $/\left(\mu \mathrm{g} \mathrm{mL}^{-1}\right)$ & \multicolumn{4}{|l|}{$5-60$} \\
\hline Regression equation & \multicolumn{4}{|c|}{$19012.33 x-51359.59$} \\
\hline Correlation coefficient $\left(r^{2}\right)$ & \multicolumn{4}{|l|}{0.9991} \\
\hline Sensitivity: & & & & \\
\hline Limit of Detection (LOD) $/\left(\mu \mathrm{g} \mathrm{mL}^{-1}\right)$ & \multicolumn{4}{|l|}{2.22} \\
\hline Limit of Quantification (LOQ)/( $\left.\mu \mathrm{g} \mathrm{mL}^{-1}\right)$ & \multicolumn{4}{|l|}{6.74} \\
\hline \multicolumn{5}{|l|}{ Precision (\% RSD) } \\
\hline Intraday $(\mathrm{n}=3) /\left(\mu \mathrm{g} \mathrm{mL}^{-1}\right)$ & $10(0.44)$ & & $20(2.01)$ & \\
\hline Inter-day $(\mathrm{n}=3) /\left(\mu \mathrm{g} \mathrm{mL}^{-1}\right)$ & $10(2.15)$ & & $20(0.73)$ & \\
\hline Accuracy: & Theoretical content $/(\mu \mathrm{g})$ & Found Content $/(\mu \mathrm{g})$ & Recovery/(\%) & Mean recovery (\%RSD) \\
\hline $\begin{array}{l}\text { Ethanol extract (spiked } 0.25 \mu \mathrm{g} \text { ) (Initial } \\
\text { content }=6.50 \mu \mathrm{g})\end{array}$ & 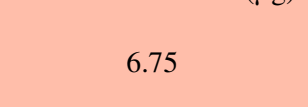 & $\begin{array}{l}6.84 \\
6.74 \\
672\end{array}$ & $\begin{array}{l}101.33 \\
99.85 \\
99.55\end{array}$ & $100.24(0.95)$ \\
\hline $\begin{array}{l}\text { Methanol extract (spiked } 0.25 \mu \mathrm{g} \text { ) } \\
\text { (Initial content }=12.48 \mu \mathrm{g} \text { ) }\end{array}$ & 12.73 & $\begin{array}{l}12.75 \\
12.52 \\
12.77\end{array}$ & $\begin{array}{c}100.16 \\
98.35 \\
100.31\end{array}$ & $99.61(1.09)$ \\
\hline
\end{tabular}


TABLE-2

ROBUSTNESS OF THE METHOD

\begin{tabular}{lcc}
\hline \multicolumn{1}{c}{ Variations } & $\begin{array}{c}\text { Peak area (RSD\%) } \\
(\mathrm{n}=3)\end{array}$ & $\begin{array}{c}\text { R.T. (RSD\%) } \\
(\mathrm{n}=3)\end{array}$ \\
\hline Acid concentration $( \pm 0.5 \%)$ & 0.9077 & 1.7171 \\
$\begin{array}{l}\text { Column oven temperature } \\
\left( \pm 2{ }^{\circ} \mathrm{C}\right)\left(32^{\circ} \mathrm{C}\right)\end{array}$ & 1.9476 & 1.8058 \\
$28^{\circ} \mathrm{C}$ & 0.8018 & 0.8208 \\
\hline
\end{tabular}

using different energy assisted extraction techniques like MAE (Microwave assisted extraction) and UAE (Ultrasonic assisted extraction) were also studied changing one parameter at a time keeping the other constant. It was observed that the maximum extraction for rosmarinic acid was achieved by applying energy assisted extraction techniques (Fig. 2).

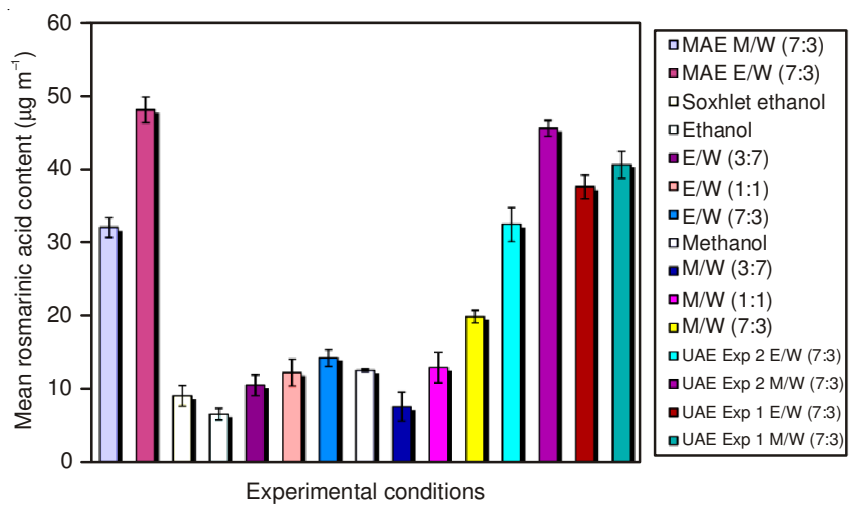

Fig. 2. Comparison of different extraction techniques showing the maximum extractive values for rosmarinic acid with multivariate use of solvent composition and energy parameters; MAE Microwave assisted extraction, UAE Ultrasonic assisted extraction, E/W Ethanol/Water, M/W Methanol/Water

Extraction methodologies: At the initial bench scale level different extraction techniques were studied. The extractive coefficients of different solvents were studied keeping in mind the possibility for its commercial application. The extraction efficiency of the plant has been shown to be better in alkanol solvents. It was also observed that the extractive affinity decreased in either the alkanol solvents or pure water when applied separately. Thus, a mixture of the two in different ratios was experimented in detail to evaluate the increasing extractive value for a successful combination. The optimum ratio thus achieved in the bench scale studies was further tested to assess the enrichment in the rosmarinic acid content in the extracts by application of different energy assisted extractions.

The extraction efficiency of rosmarinic acid from the leaves of $R$. officinalis, using different extraction methodologies viz. cold percolation, soxhlet extraction, ultrasonication and microwave extractions were studied. During optimization, extraction of target rosmarinic acid at different operating conditions in ultrasonic pulse $(10 \mathrm{~s} / 10 \mathrm{~s}$ pulse mode at 60 and $80{ }^{\circ} \mathrm{C}$ for 10,30 and 60 min extraction time), microwave extraction $\left(900,600,450,300 \mathrm{~W}\right.$ at $50{ }^{\circ} \mathrm{C}$ for 3 min extraction time) were studied. The result of extraction efficiency of solvents and suitability of extraction techniques are summarized in (Table-3) which showed that optimum amount of rosmarinic acid was obtained in ultrasonic experiment no $2(3 \times 100 \mathrm{~mL}$, $10 \mathrm{~s} / 10 \mathrm{~s}$ pulse mode at $80{ }^{\circ} \mathrm{C}$ for $60 \mathrm{~min}$ with $7: 3$ methanol/ water ratio), microwave $(3 \times 100 \mathrm{~mL}$ at $900 \mathrm{~W}$ for $3 \mathrm{~min}$ at $7: 3$ ethanol/water ratio) at the operating conditions as given in parentheses.

Rapid downstream processing of cold percolated extracts for further enrichment of rosmarinic acid content: Even though the rosmarinic acid content in the rosemary leaves collected was on a lower side, which may be due to the variation in agro-climatic conditions it was further investigated for rapid enrichment which can be upgraded to pilot scale conditions. The maximum extraction efficiency achieved during the prior art bench scale using $70 \%$ methanolic and $70 \%$ ethanolic condition was again re-considered and separately studied for further enrichment of the crude extracts prepared at the normal room temperature conditions. Previously reported process for the isolation of rosmarinic acid was done by extraction with water and then it was followed by partitioning of the extract with di-isopropyl ether ${ }^{18}$.

The enrichment was effective with various energy involved process and hence time consuming. Further with an urge for implementation at the industrial scale, the purification or enhancement in the content was thought to be processed by liquid partitioning applying solid-matrix base. Our present method involves the use of newly developed solid-matrix partition technology which depends on the principle of adsorption chromatography ${ }^{24}$. As compared to liquid-liquid partioning the application of solid-matrix technique using a

TABLE-3

EXTRACTABILITY OF DIFFERENT SOLVENTS AND STUDY OF DIFFERENT EXTRACTION TECHNIQUES FOR ROSMARINIC ACID ANALYSIS FROM THE LEAVES OF ROSEMARY PLANT

\begin{tabular}{|c|c|c|c|c|c|c|c|c|}
\hline \multirow[b]{2}{*}{ Techniques } & \multicolumn{8}{|c|}{ Amount of marker compound rosmarinic acid quantified mean $\left(\mu \mathrm{g}^{-1}\right)^{\mathrm{a}}$ solvents } \\
\hline & $\mathrm{MeOH}$ & $\begin{array}{c}\mathrm{MeOH}: \mathrm{H}_{2} \mathrm{O} \\
(7: 3) \\
\end{array}$ & $\begin{array}{c}\mathrm{MeOH}: \mathrm{H}_{2} \mathrm{O} \\
(1: 1)\end{array}$ & $\begin{array}{c}\mathrm{MeOH}: \mathrm{H}_{2} \mathrm{O} \\
(3: 7)\end{array}$ & $\mathrm{EtOH}$ & $\begin{array}{c}\text { EtOH: } \mathrm{H}_{2} \mathrm{O} \\
(7: 3)\end{array}$ & $\begin{array}{c}\text { EtOH: } \mathrm{H}_{2} \mathrm{O} \\
(1: 1)\end{array}$ & $\begin{array}{c}\text { EtOH: } \mathrm{H}_{2} \mathrm{O} \\
(3: 7)\end{array}$ \\
\hline \multirow[t]{2}{*}{ Cold Percolation } & 12.4824 & 19.8347 & 12.8507 & 7.5348 & 6.5045 & 14.1674 & 12.1582 & 10.4705 \\
\hline & \pm 0.16 & \pm 0.84 & \pm 2.07 & \pm 1.98 & \pm 0.80 & \pm 1.13 & \pm 1.83 & \pm 1.42 \\
\hline Hot Percolation & $N S^{b}$ & $\mathrm{NS}^{\mathrm{b}}$ & $N S^{b}$ & $\mathrm{NS}^{\mathrm{b}}$ & $9.0108 \pm 1.38$ & $\mathrm{NS}^{\mathrm{b}}$ & $\mathrm{NS}^{\mathrm{b}}$ & $N S^{b}$ \\
\hline \multicolumn{9}{|c|}{ Optimized solvent selection as per the maximum extracted analyte in cold extraction technique } \\
\hline $\begin{array}{l}\text { Ultrasonic assisted } \\
\text { extraction Exp1 }\end{array}$ & $\mathrm{NS}^{\mathrm{b}}$ & $40.5887 \pm 1.84$ & $\mathrm{NS}^{\mathrm{b}}$ & $\mathrm{NS}^{\mathrm{b}}$ & $\mathrm{NS}^{\mathrm{b}}$ & $37.5680 \pm 1.62$ & NS & $\mathrm{NS}^{\mathrm{b}}$ \\
\hline $\begin{array}{l}\text { Ultrasonic assisted } \\
\text { extraction Exp } 2\end{array}$ & $\mathrm{NS}^{\mathrm{b}}$ & $45.5489 \pm 1.09$ & $N S^{b}$ & $\mathrm{NS}^{\mathrm{b}}$ & $\mathrm{NS}^{\mathrm{b}}$ & $32.4298 \pm 2.31$ & $N S^{b}$ & $\mathrm{NS}^{\mathrm{b}}$ \\
\hline $\begin{array}{l}\text { Microwave assisted } \\
\text { extraction }\end{array}$ & $\mathrm{NS}^{\mathrm{b}}$ & $32.0034 \pm 1.37$ & $N S^{b}$ & $\mathrm{NS}^{\mathrm{b}}$ & $\mathrm{NS}^{\mathrm{b}}$ & $48.0923 \pm 1.74$ & $\mathrm{NS}^{\mathrm{b}}$ & $N S^{b}$ \\
\hline
\end{tabular}


filtration aid gives better results in terms of mass transfer and extraction kinetics. The initial crude extract although having a lot of non-homogenous dispersed phases was adsorbed to celite and dried under reduced pressure. The vacuum concentrated extract was further loaded onto a small VLC assembly and partitioned with 3 washes of ethyl acetate sufficient to extract the adhering impurities or major compounds present at a considerable amount in the rosemary leaves of Indian origin. The consecutive wash with methanol contained the major concentration of the analyte with lowest interfering compound matrix with a 25 fold enhancement in the enrichment of rosmarinic acid content as compared to the initial rosmarinic acid content in the extract. The comparative chromatograms of different washes and enrichment data diagram have been shown (Figs. 3 and 4).

Thus this study observed that acoustic assisted extraction and MAE improved the extraction of rosmarinic acid from rosemary leaves apart from the other extraction techniques which have been reported. The selection of solvents and appropriate aqueous solvent ratio significantly improved the rosmarinic acid content of the extracts; methanol/water and ethanol/water ratio $(7: 3)$ was found to be the most efficient solvent for ultrasonic extraction and microwave assisted extraction of rosmarinic acid in rosemary leaves. Furthermore, the current HPLC method also substantiates the effective determination of rosmarinic acid content and suffices the determination of other bioactive constituents for future studies.
The current study proposes a simple, rapid, low-cost, ecofriendly and efficient protocol for the extraction and subsequent enrichment of rosmarinic acid content by the use of new advertent solid-matrix partitioning technology. This methodology thus suffices the need for a standardized eco-friendly solvent extraction and enrichment mediated protocol for the effective extraction and quantification of rosmarinic acid.

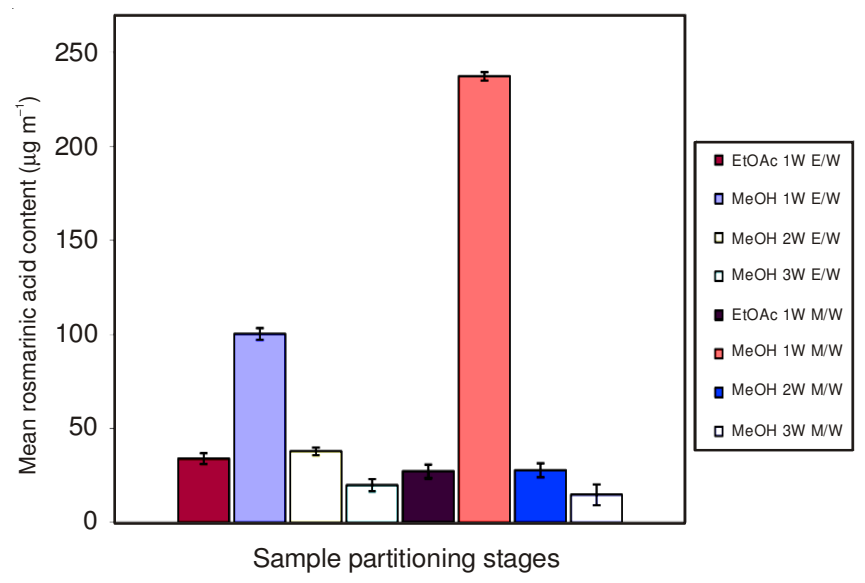

Fig. 4. Comparative bar diagram for the enrichment of rosmarinic acid content by the use of solid-matrix adsorption technology; $1 \mathrm{~W} 1^{\text {st }}$ Wash, $2 \mathrm{~W} 2^{\text {nd }}$ Wash, $3 \mathrm{~W} 3^{\text {rd }}$ Wash, E/W Ethanol/Water 7:3, M/W Methanol/Water 7:3
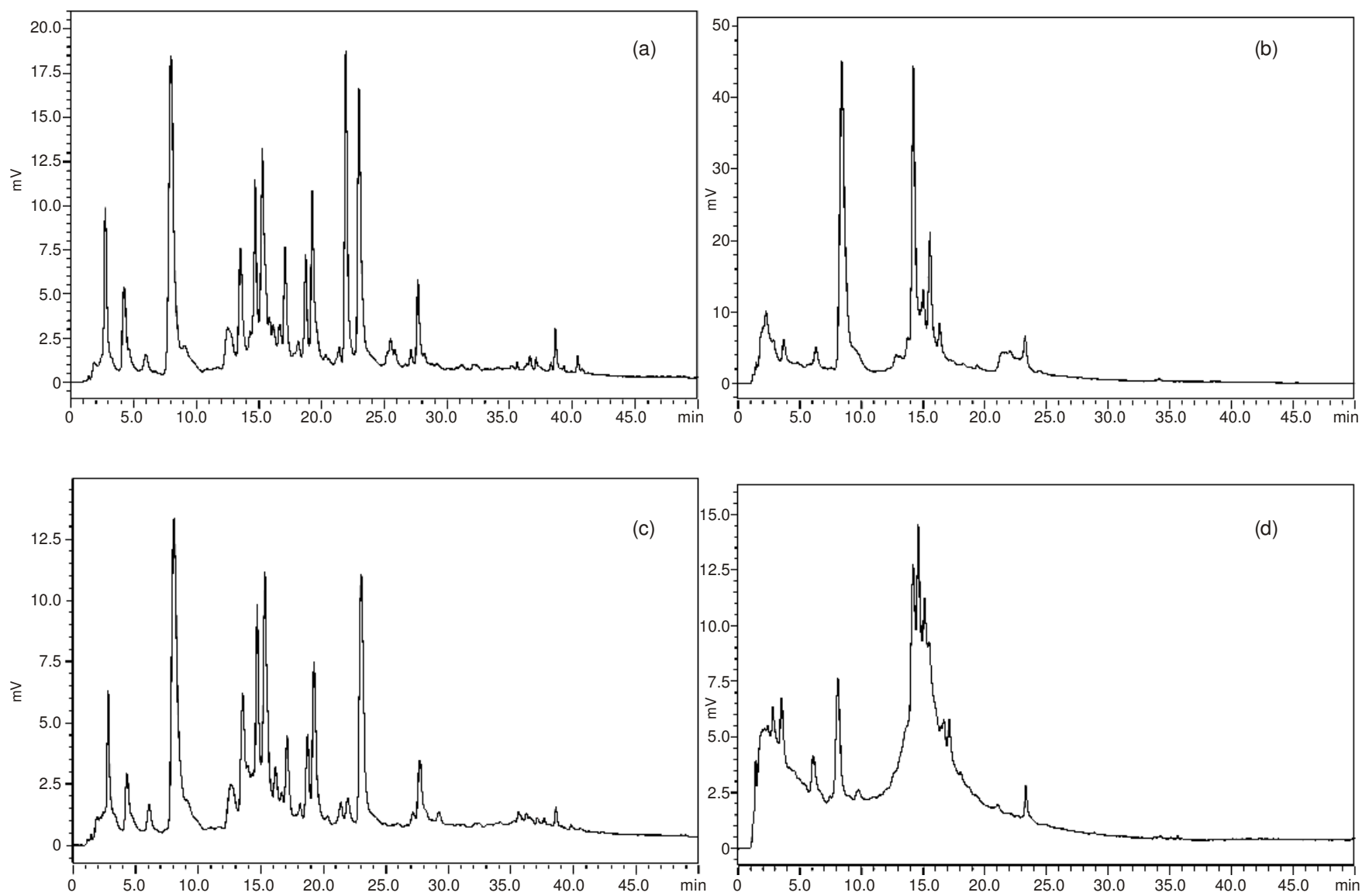

Fig. 3. Representative HPLC chromatograms of solid-matrix partitioned extracts (a) Ethyl acetate $1^{\text {st }}$ wash of cold percolated $70 \%$ ethanolic extract (b) $\mathrm{MeOH} 1^{\text {st }}$ wash. (c) Ethyl acetate $1^{\text {st }}$ wash of cold percolated $70 \%$ methanolic extract and, (d) $\mathrm{MeOH} 3^{\text {rd }}$ wash 


\section{REFERENCES}

1. K. Schwarz and W. Ternes., Z. Lebensm. Unters. Forsch, 95, 95 (1992).

2. O. I. Aruoma, B. Halliwell, R. Aeschbach and J. Loligers, Xenobiotica, 22, 257 (1992).

3. E.N. Frankel, S. Huang, R. Aeschbach and E. Prior, J. Agric. Food. Chem., 44, 131 (1996)

4. W. Zheng and S.Y. Wang, J. Agric. Food. Chem., 49, 5165 (2001).

5. M.R. Al-Sereiti, K.M. Abu-Amer and P. Sen, Ind. J. Exp. Biol., 37, 124 (1999).

6. H. Ito, T. Miyazaki, M. Ono and H. Sakurai, Bioorg. Med. Chem., 6, 1051 (1989).

7. H. Takeda, M. Tsuji, T. Matsumiya and M. Kubo, Nihon Shinkei Yakurigaku Zasshi, 22, 15 (2002).

8. R.C. Wren, Potter's New Encyclopedia of Botanical Drugs and Preparations, The CW Daniel Company Ltd., (England) (1988).

9. M.L. Scarpati and G. Oriente, Ricerca Sci., 28, 2392 (1958).

10. K. Triantaphyllou, G. Blekas and D. Boskou, Int. J. Food. Sci. Nutr., 52, 313 (2001).

11. M.H. Yu, J.H. Choi, I.G. Chae, H.G. Im, S. A. Yang, K. More, I.S. Lee and J. Lee, Food. Chem., 136, 1047 (2013).
12. M. Petersen and M.S.J. Simmonds, Phytochemistry, 62, 121 (2003).

13. M.J. del Bano, J. Lotente, J. Castillo, O. Benavente-García, J.A. del Río, A. Ortuño, K.W. Quirin and D. Gerard, J. Agric. Food. Chem., 51, 4247 (2003).

14. A. Sanchez-Medina, C.A. Etheridge, G.E. Hawkes, P.J. Hylands, B.A. Pendry, M.J. Hughes and O. Corcoran, J Pharm Sci-US, 10, 455 (2007).

15. H. Wang, G.J. Provon and K. Heliwell, Food. Chem., 87, 307 (2004).

16. M.L. Scarpati and G. Oriente, Tetrahedron, 4, 43 (1958).

17. Gestirner and Schiemenz. Sci. Pharm., 37, 40 (1969).

18. B. Christ and K. Kurt, US Patent 4,354,0345 (1982).

19. M. Herrero, M. Plaza, A. Cifuentes and E. Ibánez, J. Chromatogr. A, 1217, 2512 (2010)

20. ICH (Q2), Proceedings of the International Conference on Harmonization, IFPMA, Geneva (2005).

21. M. Thompson, SL.R. Ellison and R. Wood, Pure Appl. Chem., 74, 835 (2002).

22. R.G.D. Steele and J.H. Torrie, Principles and Procedures of Statistics, McGraw Hill, New York (1980).

23. ICH Harmonized Tripartite Guideline: Validation of Analytical Procedures: Text and Methodology Q2 (R1), October, Step 4 version (1994).

24. S. Tandon, A. Chatterjee, S.K. Chattopadhyay, R. Kaur and A.K. Gupta, Ind. Crop. Prod., 31, 335 (2010). 